\title{
Preferences for Advance Directives in Korea
}

\author{
So-Sun Kim, ${ }^{1}$ Won-Hee Lee, ${ }^{1}$ JooYoung Cheon, ${ }^{2}$ Jung-Eun Lee, ${ }^{2}$ KiSun Yeo, ${ }^{2}$ and JuHee Lee ${ }^{1}$ \\ ${ }^{1}$ Nursing Policy Research Institute, College of Nursing, Yonsei University, Seoul 120-752, Republic of Korea \\ ${ }^{2}$ College of Nursing, Yonsei University, Seoul 120-752, Republic of Korea \\ Correspondence should be addressed to JuHee Lee, jhl@yuhs.ac
}

Received 14 November 2010; Revised 15 May 2011; Accepted 30 June 2011

Academic Editor: John Daly

Copyright () 2012 So-Sun Kim et al. This is an open access article distributed under the Creative Commons Attribution License, which permits unrestricted use, distribution, and reproduction in any medium, provided the original work is properly cited.

\begin{abstract}
Background. The goal of advance directives is to help patients retain their dignity and autonomy by making their own decisions regarding end-stage medical treatment. The purpose of this study was to examine preferences of advance directives among general population in Korea. Method. A descriptive cross-sectional survey was performed from October 2007 to June 2008 in Seoul, Korea. A total of 336 city-dwelling adults self-administered the questionnaire and returned it via mail. Data analyses were conducted using SPSS 17.0. Results. Subjects reported the need for healthcare providers' detailed explanations and recommendations regarding end-of-life care. When there is no hope of recovery and death is imminent, most subjects did not want to receive cardiopulmonary resuscitation nor an IV or tube feeding. However, most of the subjects wanted pain management care. Conclusions. The present study showed that many Korean people have an interest in advance directives. The results show that the autonomy and dignity of patient have increased in importance. To provide better end-of-life care, there is a need to educate patients on the definition and intent of an advance directive. Additional proactive communication between patients and their caregivers should be educated to healthcare providers.
\end{abstract}

\section{Background}

An advance directive $(\mathrm{AD})$ is an "oral or written statement in which people declare their treatment preferences in the event that they lose decision-making capacity" [1]. ADs are used to enhance the autonomy of patients for when they are unable to make medical decisions or express their preferences by themselves [2]. Therefore, ADs become a kind of a truism to assert respect for the patient in regard to their autonomy [3]. Capron [4] has stated that when a patient has a properly executed $\mathrm{AD}$, the patient would, in theory, alleviate much of the uncertainty that often paralyzes physicians and family members (or other surrogate decision makers) and would facilitate the resolution that best reflects their true wishes regarding their care [5].

In the USA, ADs have received widespread attention ever since the enactment of the Patient Self-Determination Act (PSDA, Public Law no. 101-508) in 1991 [6]. Various laws related to ADs give patients the right to express their wishes for end-of-life situations. The PSDA ensures that advance care planning is documented in the patient's medical record in advance and makes it as a formal document. The estimates of those with ADs vary from 16 to $26 \%$ in the USA [7]. Healthcare providers consistently try to apply ADs to older patients or terminal patients that are in a clinical setting as an attempt to improve the quality of end-of-life care by communicating with both the patients and their family members.

In Korea, with more than 24,600 deaths annually, the percentage of deaths that occur in hospitals increased from $28.5 \%$ in 1998 to $63.7 \%$ in 2008 [8]. Culturally, Korean people generally feel uncomfortable talking about death and have traditionally made medical decisions based on what is best for the family rather than allowing the patient to decide for themselves [9]. In other words, most of the patients in Korea have little opportunity to prepare ADs [10]. A recent survey has shown that $84 \%$ of the decisions made in regard to ADs are made by physicians [11]; however, another survey has found that $\mathrm{AD}$ decisions are mostly made by the offspring or spouse of the patient [12-14].

However, there is an increasing interest in death and of end-of-life care as a result of our increased life span. A survey of cancer patients in Korea has shown that $96.1 \%$ of patients want to be made aware of their (end-of-life) 
condition. However, only $78.3 \%$ of family members want to inform the patients of their condition [15]. Thus, a conflict exits between the opinions of the patients and their families.

Korea had its first legal exposure to end-of-life issues in 1997 with the Boramae Hospital case [5]. In this case, physicians were unable to persuade the patient's wife to maintain the required therapies and were later charged and found guilty of discharging their postoperative patient after discontinuing the life-sustaining therapy. Prior to this case, physicians in Korea had been able to withdraw life-sustaining therapy with the consent of the patient's delegate [16]. As recently as May 2009, the Korean Supreme Court recognized the validity of $\mathrm{ADs}$ as a result of the nation's first civil case concerning the withdrawal of life-sustaining treatment for an incompetent patient [5]. The legislation of ADs regarding removal of life-sustaining devices from comatose patients that have no hope of resuscitation has been dealt with in the Supreme Court. In regard to the issue of stopping meaningless end-of-life treatments in terminally ill patients, the National Evidence-based Healthcare Collaborating Agency (NECA) of Korea held three consecutive consensus meetings in July 2009. The contents of these meetings were stated as follows. (1) Basic care such as fluids, nutritional support, and pain control should be maintained. (2) When a terminally ill patient expresses his or her wishes to refuse cardiopulmonary resuscitation $(\mathrm{CPR})$ or ventilator support, the $\mathrm{CPR}$ or the ventilation care can be stopped. (3) The patient can express their wishes regarding life-sustaining treatments other than cardiopulmonary resuscitation or ventilator support. (4) The physician should take the patient's wishes into consideration when making a medical decision. (5) Euthanasia and physician-assisted suicide are unacceptable [17].

As social interests regarding ADs increase, a few researchers have examined AD issues in Korea [18-21]. A survey of adults and healthcare providers shows that $78.8 \%$ of participants express interest in ADs [22]. However, cultural beliefs or values can have differing impacts on the attitudes regarding ADs among people in Korea [23-25]. Since death is not a topic that is readily discussed or expressed, people may believe that it is wrong to refuse medical treatment at the end-of-life stage. Furthermore, there have only been a few studies that have examined the attitudes or the perceptions of death, which has resulted in a limited view of ADs in this population.

By providing an $\mathrm{AD}$ in a document, patients are able to make their wishes known as well as provide both clarity and comfort to the family members [26]. With this view of ADs, this study aimed to examine how ADs were perceived in the general population of Korea in order to ultimately stimulate future research in this area.

\section{Methods}

2.1. Design. A descriptive cross-sectional survey was performed to investigate the attitudes and perceptions of people in Korea regarding ADs. Data were collected using convenience sampling from Oct 2007 to June 2008 using a mailed survey. Permission from the Institutional Review Board (IRB) was obtained prior to data collection from university setting. In order to meet ethical considerations, participants received a document explaining of anonymity, confidentiality, rights to withdraw freely, and benefit/risk of completing the questionnaire. Informed consent was obtained from each participant.

2.2. Sample and Data Collection. Participants in this study were adults (age $\geq 18$ years) residents of Seoul, Korea who had agree to participate. In order to conduct a representative survey, Moser and Kalton's formula [27] was used to determine the sample size and the acceptable margin of error was set at three percent $(0.03)$ for this study. According to this formula, given that the sampling population (people preferred to get palliative care) was about $85 \%$ in Korea [28], a sample size of at least 141 participants were necessary to give significant results.

We first contacted the heads of public offices, companies, and resident associations in Seoul. After receiving approval from these people, we then mailed the study materials and a formal consent form to all of the associated members. One public office, one company, and two resident associations were included in this study. All of the participants provided signed informed consent. Only eligible patients who agreed to participate in the study were included. Among them, 336 subjects self-administered the questionnaire and returned it to us by mail. A small incentive was provided at the time of initial contact in order to increase the completion rate.

2.3. Questionnaire. A questionnaire was developed and validated by Miyata et al. [29], in which respondents were asked about their preferences and attitudes regarding ADs. Respondents were also asked about their preferences regarding treatment, which were translated from actual living will declarations from people in the USA. The original questionnaire items were as follows: "If my condition is determined to be terminal and incurable, I do want lifesustaining procedures that serve only to prolong the process of my dying," "If I am in an irreversible or incurable persistent vegetative state, I do want cardiac resuscitation," "If I am in an irreversible or incurable persistent vegetative state, I do want artificial nutrition and hydration," and "I want my life to be prolonged to the greatest extent possible." The questionnaire asked respondents to what extent they wanted to express their preferences regarding treatment, how they would like to discuss treatment preferences with their proxy, and to what extent their proxy should respect their preferences regarding treatment [29].

Since the questionnaire is in Japanese and no Korean or English version existed for use in our study, we received permission from the author to translate the questionnaire from Japanese into Korean. Two bilingual (Japanese and Korean) native Korean-speaking nursing professionals translated the questionnaire into Korean. Any Japanese phrases that were difficult for them to understand were translated after consensus. Two other bilingual native Japanese-speaking translators then performed the back translations of the first Korean version. Any differences between the back-translated version and the original version were further discussed, and applicable modifications were made. 
To test the item clarity and content validity, the translated version was submitted to five nursing professionals that were familiar with the subject matter referenced in the questionnaire. The content validity of the questionnaire was assessed by calculating the content validity index (CVI) [30]. The overall CVI was 0.90 , which indicated satisfactory agreement of the Korean version among the professionals. The translated version was then tested on a pilot group that consisted of 20 adults. After they had completed the questionnaire, they were asked if the translated questions were easy to understand and their responses were used to determine that no further revisions were required.

2.4. Data Analysis. Data were entered into SPSS 17.0, and an investigator confirmed the accuracy of the data entry by comparing the answers with those in the original questionnaires. Descriptive analyses were conducted to measure the sociodemographic characteristics and preferences for ADs. Chi-square tests were performed to assess the differences in the preferences for end-of-life treatment according to sociodemographic characteristics.

\section{Findings}

Table 1 presents the sociodemographic characteristics of the study participants. A total of 336 subjects completed and returned their questionnaires $(44.3 \%$ were men). The mean age of the participants was 43 years with a SD of 9.5 (range $18-74$ years). Many of the subjects $(n=199,59.2 \%)$ had a greater than university level of education, and many rated their health as neutral $(n=181,53.9 \%)$. Only 31\% $(n=$ 104) of subjects answered that they were in good or very good health. Approximately half of the participants claimed their socioeconomic status to be neutral $(n=178,53 \%)$, and approximately $33 \%$ of respondents did not affiliate with any religion. More than half of the subjects had experienced the death of a loved one $(n=241,71.7 \%)$. More than $50 \%$ of the subjects reported that they had not ever given thought to their end-stage treatment desires $(n=196,58.3 \%)$, and most of the subjects did not have a will $(n=279,83 \%)$.

Subjects $(n=125,37 \%)$ reported the need for an explanation of ADs from their healthcare provider. Additionally, they expressed desire for $\mathrm{AD}$ recommendation from their healthcare provider if they were ever to be in an advanced disease state $(n=205,61 \%)$. Table 2 presents the preferences for end-of-life treatment under specific circumstances. More than $60 \%(n=213)$ of the subjects reported that they did not want cardiopulmonary resuscitation if they were ever to be at the end-of-life stage without any hope of recovery. The majority of subjects did not want to have an IV or tube feeding $(n=228,67.9 \%)$. However, if there is no hope of any recovery and death is imminent, most of the study subjects wanted to receive pain management $(n=200$, $59.5 \%)$ while $64.6 \%(n=217)$ of the subjects did not want any type of aggressive life-sustaining treatment. Interestingly, $8.9 \%(n=30)$ wanted to receive active medical treatment regardless of their health status while $60.7 \%(n=204)$ did not. Additionally, in cases in which subjects cannot make their own decisions regarding treatment, $40 \%(n=134)$ of
TABLE 1: Sociodemographic characteristics $(N=336)$.

\begin{tabular}{|c|c|c|}
\hline Variable & Frequency $(n)$ & Percentage (\%) \\
\hline \multicolumn{3}{|l|}{ Age } \\
\hline$\leq 30$ years old & 35 & 10.4 \\
\hline $31-40$ & 93 & 27.7 \\
\hline $41-50$ & 152 & 45.2 \\
\hline $51-60$ & 45 & 13.4 \\
\hline$\geq 61$ years old & 11 & 3.3 \\
\hline \multicolumn{3}{|l|}{ Gender } \\
\hline Male & 149 & 44.3 \\
\hline Female & 187 & 55.7 \\
\hline \multicolumn{3}{|l|}{ Education } \\
\hline Middle school & 18 & 5.4 \\
\hline High school & 92 & 27.4 \\
\hline College & 22 & 6.5 \\
\hline$\geq$ university & 199 & 59.2 \\
\hline Other & 5 & 1.5 \\
\hline \multicolumn{3}{|c|}{ Self-reported health status } \\
\hline Very good & 59 & 17.6 \\
\hline Good & 45 & 13.4 \\
\hline Neutral & 181 & 53.9 \\
\hline Bad & 48 & 14.3 \\
\hline Very bad & 3 & 0.9 \\
\hline \multicolumn{3}{|c|}{ Socioeconomic status } \\
\hline Fairly good & 87 & 25.9 \\
\hline Neutral & 178 & 53 \\
\hline Fairly bad & 71 & 21.1 \\
\hline \multicolumn{3}{|l|}{ Religion } \\
\hline None & 112 & 33.3 \\
\hline Buddhism & 54 & 16.1 \\
\hline Catholicism & 33 & 9.8 \\
\hline Christianity & 132 & 39.3 \\
\hline Other & 5 & 1.5 \\
\hline \multicolumn{3}{|c|}{$\begin{array}{l}\text { Past experiences of } \\
\text { separation by death }\end{array}$} \\
\hline Yes & 241 & 71.7 \\
\hline No & 95 & 28.3 \\
\hline \multicolumn{3}{|l|}{ Having a will } \\
\hline Yes & 57 & 17 \\
\hline No & 279 & 83 \\
\hline Total & 336 & 100 \\
\hline
\end{tabular}

the subjects wanted their proxy and doctor decide on the care plan while $28 \%(n=95)$ of the subjects wanted the proxy alone to make a care decisions.

Table 3 lists the attitudes of subjects toward ADs. The results show that $69.3 \%(n=233)$ of the participants reported that they would verbally express their medical preferences, while $60.1 \%(n=202)$ of the subjects wanted a written document to state these preferences. Forty percent of the subjects $(n=132)$ wanted to express their treatment 
TABle 2: Preferences for end-of-life treatment $(N=336)$.

\begin{tabular}{|c|c|c|c|}
\hline & Yes $(\%)$ & $\begin{array}{l}\text { I do not } \\
\text { know }(\%)\end{array}$ & No $(\%)$ \\
\hline $\begin{array}{l}\text { If there is no hope of my recovery and the death is drawing near, I want } \\
\text { to be treated for relieving pain although that treatment can reduce my } \\
\text { life (Preference item 1) }\end{array}$ & $200(59.5)$ & $64(19)$ & $72(19.2)$ \\
\hline $\begin{array}{l}\text { If there is no hope of my recovery and the death is near, I want to be } \\
\text { treated aggressively to extend or sustain my life even with no effect for } \\
\text { recovery (Preference item 2) }\end{array}$ & $34(10.1)$ & $85(25.3)$ & $217(64.6)$ \\
\hline $\begin{array}{l}\text { If I am living as a vegetarian, I want to be given cardiopulmonary } \\
\text { resuscitation using defibrillator (Preference item } 3 \text { ) }\end{array}$ & $54(16.1)$ & $69(20.5)$ & $213(63.4)$ \\
\hline $\begin{array}{l}\text { If I am living as a vegetarian, I want to be given IV therapy and } \\
\text { nasogastric tube feeding (Preference item } 4 \text { ) }\end{array}$ & $23(6.8)$ & $85(25.3)$ & $228(67.9)$ \\
\hline I want to be treated to extend my life in any case (Preference item 5) & $30(8.9)$ & $102(30.4)$ & $204(60.7)$ \\
\hline
\end{tabular}

TABLE 3: Attitudes regarding advance directives $(N=336)$.

\begin{tabular}{|c|c|c|c|c|c|}
\hline & Agree a lot (\%) & $\begin{array}{c}\text { Agree a little } \\
(\%)\end{array}$ & $\begin{array}{c}\text { Neither agree } \\
\text { nor disagree } \\
(\%)\end{array}$ & $\begin{array}{c}\text { Disagree a little } \\
(\%)\end{array}$ & $\begin{array}{c}\text { Disagree a lot } \\
(\%)\end{array}$ \\
\hline $\begin{array}{l}\text { I want to prepare a verbal } \\
\text { promise indicating medical } \\
\text { treatment preference if } \\
\text { needed }\end{array}$ & $84(25)$ & $149(44.3)$ & $68(20.2)$ & $28(8.3)$ & $7(2.1)$ \\
\hline $\begin{array}{l}\text { I want to prepare a } \\
\text { document describing } \\
\text { medical treatment } \\
\text { preference if needed }\end{array}$ & $90(26.8)$ & $112(33.3)$ & $82(24.4)$ & 39 (11.6) & $13(3.9)$ \\
\hline $\begin{array}{l}\text { I want to have a power of } \\
\text { attorney for possible } \\
\text { medical treatment }\end{array}$ & $113(33.6)$ & $124(36.9)$ & 64 (19) & $26(7.7)$ & $9(2.7)$ \\
\hline $\begin{array}{l}\text { I want to propose whether } \\
\text { someone notify me if I have } \\
\text { a cancer or chronic illness }\end{array}$ & $167(49.7)$ & $121(36)$ & $29(8.6)$ & $16(4.8)$ & $3(0.9)$ \\
\hline
\end{tabular}

preferences generally rather than concretely. Most of the subjects $(n=288,85.7 \%)$ wanted direct notification of disease in cases of cancer or chronic disease. More than $80 \%$ of the subjects did not have a proxy $(n=277)$; however, many expressed the desire to obtain such an agent to make medical treatment decisions $(n=237)$.

Chi-square analysis showed that only education status was identified as being significantly associated with the preferences for end-of-life treatment (Table 4). The participants that had a higher level of education were more likely to want pain management even though the treatment may reduce their life expectancy $\left(x^{2}=14.296, P<0.001\right)$. Education level was categorized into two groups: low level (middle or high school graduation) and high level (college or university graduation). Other sociodemographic characteristics such as age, gender, self-reported health status, socioeconomic status, and religion were not significantly associated with treatment preferences.

Table 5 shows that most participants indentified their spouse as their first choice as their proxy regarding medical treatment $(n=243,72.3 \%)$. Subjects also wanted to be respected by their proxy regarding their treatment preferences $(n=260,77.4 \%)$. In regard to treatment preferences, most respondents expressed the desire for multiple conversations with their respective proxy regarding treatment preferences ( $n=235,70 \%)$, especially in the case of advanced disease. If the proxy has a different opinion than does the patient's physician, then many subjects preferred the opinion of the physician $(n=174,51.4 \%)$.

\section{Discussion}

With the rapid increase in the number of older people in Korea, health professionals and researchers should have a better understanding of the preferences and attitudes of the general population in regard to ADs. The present study examined the understanding of ADs among Koreans. The findings suggested that subjects acknowledge the importance of patient autonomy and dignity when deciding on endof-life care. More than half of the subjects wanted pain management as an end-of-life treatment, but they did not want aggressive medical treatments such as CPR, IV, or tube 
TABLe 4: Preferences for end-of-life treatment by sociodemographic characteristics $(N=336)$.

\begin{tabular}{|c|c|c|c|c|c|c|c|c|c|c|c|}
\hline \multirow{2}{*}{ Characteristics } & \multirow{2}{*}{ Categories } & \multicolumn{2}{|r|}{$\mathrm{P} 1$} & \multicolumn{2}{|r|}{$\mathrm{P} 2$} & \multicolumn{2}{|r|}{ P3 } & \multicolumn{2}{|r|}{$\mathrm{P} 4$} & \multicolumn{2}{|r|}{ P5 } \\
\hline & & $\% *$ & $x^{2}$ & $\%$ & $x^{2}$ & $\%$ & $x^{2}$ & $\%$ & $x^{2}$ & $\%$ & $x^{2}$ \\
\hline \multirow{3}{*}{ Age } & $\leq 40$ & 60.2 & \multirow{3}{*}{$\begin{array}{l}0.122 \\
(P=.941)\end{array}$} & 12.5 & \multirow{3}{*}{$\begin{array}{l}2.390 \\
(P=.303)\end{array}$} & 21.9 & \multirow{3}{*}{$\begin{array}{l}6.038 \\
(P=.050)\end{array}$} & 7.0 & \multirow{3}{*}{$\begin{array}{l}0.263 \\
(P=.958)\end{array}$} & 10.2 & \multirow{3}{*}{$\begin{array}{l}1.803 \\
(P=.407)\end{array}$} \\
\hline & $41-40$ & 58.5 & & 9.1 & & 13.3 & & 7.7 & & 6.3 & \\
\hline & $\geq 51$ & 60.7 & & 5.4 & & 9.1 & & 5.4 & & 10.7 & \\
\hline \multirow{2}{*}{ Gender } & Male & 62.4 & \multirow{2}{*}{$\begin{array}{l}0.946 \\
(P=.331)\end{array}$} & 9.4 & \multirow{2}{*}{$\begin{array}{l}0.018 \\
(P=.892)\end{array}$} & 19.5 & \multirow{2}{*}{$\begin{array}{l}2.883 \\
(P=.090)\end{array}$} & 5.4 & \multirow{2}{*}{$\begin{array}{l}1.018 \\
(P=.313)\end{array}$} & 10.7 & \multirow{2}{*}{$\begin{array}{l}0.922 \\
(P=.337)\end{array}$} \\
\hline & Female & 57.1 & & 9.8 & & 12.6 & & 8.2 & & 7.7 & \\
\hline \multirow{2}{*}{ Education } & $\leq$ high school & 45.2 & \multirow{2}{*}{$\begin{array}{l}14.296 \\
(P=.000)\end{array}$} & 9.6 & \multirow{2}{*}{$\begin{array}{l}0.087 \\
(P=.768)\end{array}$} & 12.3 & \multirow{2}{*}{$\begin{array}{l}2.072 \\
(P=.150)\end{array}$} & 7.8 & \multirow{2}{*}{$\begin{array}{l}0.220 \\
(P=.639)\end{array}$} & 5.2 & \multirow{2}{*}{$\begin{array}{l}3.122 \\
(P=.077)\end{array}$} \\
\hline & $>$ college & 66.7 & & 10.6 & & 18.4 & & 6.5 & & 11.1 & \\
\hline \multirow{3}{*}{ Self-reported health status } & Good & 59.2 & \multirow{3}{*}{$\begin{array}{l}2.322 \\
(P=.313)\end{array}$} & 8.7 & \multirow{3}{*}{$\begin{array}{l}0.451 \\
(P=.798)\end{array}$} & 21.2 & \multirow{3}{*}{$\begin{array}{l}2.839 \\
(P=.242)\end{array}$} & 7.7 & \multirow{3}{*}{$\begin{array}{l}0.202 \\
(P=.956)\end{array}$} & 7.7 & \multirow{3}{*}{$\begin{array}{l}0.384 \\
(P=.846)\end{array}$} \\
\hline & Neutral & 56.7 & & 10.7 & & 13.5 & & 6.7 & & 9.6 & \\
\hline & $\mathrm{Bad}$ & 68.6 & & 11.8 & & 16.0 & & 5.9 & & 9.8 & \\
\hline \multirow{3}{*}{ Socioeconomic status } & Fairly good & 67.8 & & 5.7 & & 14.9 & & 4.6 & & 9.3 & \\
\hline & Neutral & 57.5 & $\begin{array}{l}3.839 \\
(P=.147)\end{array}$ & 11.4 & $\begin{array}{l}2.645 \\
(P=.267)\end{array}$ & 16.6 & $\begin{array}{l}0.163 \\
(P=.922)\end{array}$ & 7.4 & $\begin{array}{l}1.076 \\
(P=.577)\end{array}$ & 8.0 & $\begin{array}{l}0.666 \\
(P=.717)\end{array}$ \\
\hline & Fairly bad & 53.5 & & 12.7 & & 17.1 & & 8.5 & & 11.3 & \\
\hline & None & 58.6 & & 6.3 & & 15.2 & & 7.1 & & 9.0 & \\
\hline & Buddhism & 61.1 & & 16.7 & & 17.0 & & 11.1 & & 11.1 & \\
\hline Religion & Catholicism & 66.7 & $\begin{array}{l}1.065 \\
(P=.925)\end{array}$ & 12.1 & $\begin{array}{l}4.803 \\
(P=.274)\end{array}$ & 9.1 & $\begin{array}{l}3.646 \\
(P=.427)\end{array}$ & 6.1 & $\begin{array}{l}1.915 \\
(P=.731)\end{array}$ & 9.1 & $\begin{array}{l}0.704 \\
(P=.935)\end{array}$ \\
\hline & Christianity & 57.6 & & 11.2 & & 17.6 & & 5.6 & & 8.0 & \\
\hline & Other & 60.0 & & 0 & & 40.0 & & 0 & & 0 & \\
\hline Past experiences of & Yes & 61.1 & 1.084 & 10.9 & 0.413 & 16.4 & 0.009 & 6.3 & 0.524 & 9.7 & 0.403 \\
\hline separation by death & No & 54.8 & $(P=.321)$ & 8.5 & $(P=.521)$ & 16.0 & $(P=.924)$ & 8.5 & $(P=.469)$ & 7.4 & $(P=.526)$ \\
\hline
\end{tabular}

P1: Preference item 1, P2: Preference item 2, P3: Preference item 3, P4: Preference item 4, and P5: Preference item 5.

* Each percent means how many participants chose yes for that item.

TABle 5: Preferences for possible power of attorney in end-of-life care $(N=336)$.

\begin{tabular}{lcc}
\hline & Frequency $(n)$ & Percentage $(\%)$ \\
\hline Spouse & 243 & 72.3 \\
Parents & 28 & 8.3 \\
Adult children & 18 & 5.4 \\
Sibling & 12 & 3.6 \\
Relatives except parents, & 9 & 2.7 \\
adult children, and sibling & 22 & 6.5 \\
Doctor & 2 & 0.6 \\
Lawyer & 336 & 100 \\
\hline Total & &
\end{tabular}

feeding. The majority of participants would like to verbally express their directives rather than use a written document. There was a strong desire for a proxy agent, and the most preferred proxy was the patient's spouse.

Caution should be exercised when interpreting the results of this study since a convenience sampling method was used in an urban area. Most of the participants were well educated and had relatively high socioeconomic status, which may have had an impact on the results. Previous studies have demonstrated that higher levels of education are associated with more positive attitudes regarding end-of-life care and communication $[31,32]$. Furthermore, this study was a cross-sectional survey of people living in a metropolitan area in Korea and the results may not be applicable to populations in other countries.

Overall, the results of this study were similar with those of previous reports. First, it was not surprising that most of subjects had not thought about issues pertaining to ADs as Asians generally do not feel comfortable dealing with endof-life issues [33-35]. However, most participants expressed the desire for an explanation of ADs if they should find themselves in a terminal disease state. Therefore, discussion of end-of-life care between patients and healthcare professionals is needed in order for there to be a better understanding of ADs in the clinical setting.

Study participants wanted to communicate with their healthcare providers to obtain knowledge regarding ADs. Furthermore, they wanted to verbally express their directives rather than use written documentation. The most common method for establishing healthcare preferences can be achieved with an informal conversation $[36,37]$. Preferences for the verbal type of directives were similar to those reported in a Japanese study. However, the use of a written document is suggested over oral ADs since such verbal directives are usually forgotten or misinterpreted or may not be directly reported to healthcare providers [33].

In addition, the results of the present study showed that when subjects need to make an end-of-life decision, the involvement of family or a physician was desired. Most of the participants chose their spouse as their proxy decision 
maker. Culturally, Asian people tend to value the opinions of their family members and that of the healthcare provider over their own personal opinion $[9,29,35,38]$ and this was reflected in the findings of the present study. Cultural values and health beliefs both have an impact on end-of-life decisions. For example, African Americans prefer to use lifesustaining methods while Asians and Hispanics focus more on what is best for the family as a whole. One reason for these cultural differences may be due to limited communication with healthcare providers, which may result in inadequate trust or a personal bias when writing down the wishes of their patients [38]. Therefore, more culturally sensitive and specific nursing care plans are warranted in this area [34, 39].

The findings of one study indicated that patient autonomy was considered important in discussions of treatment decisions [40]. Frequently, healthcare providers have used the term ADs along with DNR (do not resuscitate) when focusing on CPR status and, thus, there has been a limited provision of in-depth discussion in advanced care planning [36]. We believe that benefits of ADs are more satisfied with when patients received appropriate care. Healthcare providers should improve the care they provide to both patients and families by having a better understanding of the patient needs and experiences in regard to end-of-life treatment.

This study provided that many people in Korea have an interest in ADs, that there is a need for more education regarding ADs. There is a need for better communication between patients and caregivers to improve the end-oflife care. Future studies are needed to further examine the attitudes and preferences of healthcare providers regarding ADs compared to those of patients and caregivers.

\section{References}

[1] H. Ito, T. Nakajima, K. Itai, M. Ito, and T. Imai, “On a principal of advance directives," Gan to Kagaku Ryoho, vol. 36, no. 1, pp. 66-68, 2009.

[2] J. Cohen-Mansfield, A. Libin, and S. Lipson, "Differences in presenting advance directives in the chart, in the minimum data set, and through the staff's perceptions," Gerontologist, vol. 43, no. 3, pp. 302-308, 2003.

[3] V. Beširević, "End-of-life care in the 21st century: advance directives in universal rights discourse," Bioethics, vol. 24, no. 3, pp. 105-112, 2010.

[4] A. Capron, "Advance directives," in A Companion to Bioethics, H. Kuhse and P. Singer, Eds., Blackwell Publishing, Oxford, UK, 1999.

[5] S. Kim, K. H. Hahm, H. W. Park, H. H. Kang, and M. Sohn, "A Korean perspective on developing a global policy for advance directives," Bioethics, vol. 24, no. 3, pp. 113-117, 2010.

[6] K. B. Hirschman, K. M. Abbott, A. L. Hanlon, J. P. Bettger, and M. D. Naylor, "What factors are associated with having an advance directive among older adults who are new to longterm care services?" Journal of the American Medical Directors Association. In press.

[7] A. Wilkinson, N. Wenger, and L. R. Shugarman, Literature Review on Advance Directives, U.S. Department of Health and Human Services, Washington, DC, USA, 2007.
[8] Korean National Statistical Office, Korea Statistical Yearbook, Korea National Statistical Association, Seoul, Republic of Korea, 2008.

[9] H. R. Searight and J. Gafford, "Cultural diversity at the end of life: issues and guidelines for family physicians," American Family Physician, vol. 71, no. 3, pp. 515-522, 2005.

[10] D. S. Heo, "Patient autonomy and advance directives in Korea," Journal of the Korean Medical Association, vol. 52, no. 9, pp. 865-870, 2009.

[11] T. J. Song, K. P. Kim, and Y. Koh, "Factors determining the establishment of DNR orders in oncologic patients at a university hospital in Korea," The Korean Journal of Medicine, vol. 74, no. 4, pp. 403-410, 2008.

[12] B. Y. Shim, S. I. Hong, J. M. Park et al., "DNR order for terminal cancer patients at hospice ward," Korean Journal of Hospice and Palliative Care, vol. 7, pp. 232-237, 2004.

[13] D. Y. Oh, J. H. Kim, D. W. Kim et al., "CPR or DNR? Endof-life decision in Korean cancer patients: a single center's experience," Supportive Care in Cancer, vol. 14, no. 2, pp. 103108, 2006.

[14] D. Y. Kim, K. E. Lee, E. M. Nam et al., "Do-not-resuscitate orders for terminal patients with cancer in teaching hospitals of Korea," Journal of Palliative Medicine, vol. 10, no. 5, pp. 1153-1158, 2007.

[15] Y. H. Yun, C. G. Lee, S. Y. Kim et al., "The attitudes of cancer patients and their families toward the disclosure of terminal illness," Journal of Clinical Oncology, vol. 22, no. 2, pp. 307314, 2004.

[16] Y. S. Koh, J. M. Kang, and J. D. Armstrong, "Role of hospital ethics committee on the consultation of near the end-of-life care in a Korean university hospital," Korean Journal Medical Education, vol. 8, no. 2, pp. 182-186, 2005.

[17] National Evidence-Based Healthcare Collaborating Agency, Social Consensus on End-of- life decision in Korea, National Evidence-Based Healthcare Collaborating Agency, 2009.

[18] S. Kim, Decision making process in Do-Not-Resuscitate orders for patients with cancer, M.S. thesis, Yonsei University, Seoul, Republic of Korea, 1998.

[19] Y. Park, "A review of DNR order among terminal stage patients," Nursing Inquiry, vol. 13, no. 1, pp. 105-126, 2004.

[20] H. Park, M. Koo, and Y. Kim, "Concept analysis of DNR," Journal of Korean Academy of Nursing, vol. 36, no. 6, pp. 10551064, 2006.

[21] S. A. Hong, "An empirical study for model development concerning advance directives," Journal of the Korean Gerontological Society, vol. 30, no. 4, pp. 1197-1211, 2010.

[22] S. Hong, A study on the model of the advance directives for prolongation of life for effective application of the medical insurance finance, Ph.D. thesis, Daejeon University, Daejeon, Republic of Korea, 2004.

[23] D. K. Martin, L. L. Emanuel, and P. A. Singer, "Planning for the end of life," The Lancet, vol. 356, no. 9242, pp. 1672-1676, 2000.

[24] M. T. Nolan and V. Mock, "A conceptual framework for end-of-life care: a reconsideration of factors influencing the integrity of the human person," Journal of Professional Nursing, vol. 20, no. 6, pp. 351-360, 2004.

[25] E. Phipps, G. True, D. Harris et al., "Approaching the end of life: attitudes, preferences, and behaviors of African-American and white patients and their family caregivers," Journal of Clinical Oncology, vol. 21, no. 3, pp. 549-554, 2003. 
[26] D. D. McDonald, J. A. Deloge, N. Joslin et al., "Communicating end-of-life preferences," Western Journal of Nursing Research, vol. 25, no. 6, pp. 652-666, 2003.

[27] C. A. Moser and G. Kalton, Survey Methods in Social Investigation, Heinemann Educational Books, London, UK, 2nd edition, 1971.

[28] National Cancer Center, Public Attitudes toward Dying with Dignity, Goyang, Republic of Korea, 2008.

[29] H. Miyata, H. Shiraishi, and I. Kai, "Survey of the general public's attitudes toward advance directives in Japan: how to respect patients' preferences," BMC Medical Ethics, vol. 7, article 11, 2006.

[30] M. R. Lynn, "Determination and quantification of content validity," Nursing Research, vol. 35, no. 6, pp. 382-385, 1986.

[31] K. L. Braun and R. Nichols, "Death and dying in four Asian American Cultures: a descriptive study," Death Studies, vol. 21, no. 4, pp. 327-359, 1997.

[32] S. Matsumura, S. Bito, H. Liu et al., "Acculturation of attitudes toward end-of-life care a cross-cultural survey of Japanese Americans and Japanese," Journal of General Internal Medicine, vol. 17, no. 7, pp. 531-539, 2002.

[33] A. Akabayashi, B. T. Slingsby, and I. Kai, "Perspectives on advance directives in Japanese society: a population-based questionnaire survey," BMC Medical Ethics, vol. 4, no. 5, article 1, 2003.

[34] E. Ko and J. Lee, "End-of-life communication: ethnic differences between Korean American and non-hispanic white older adults," Journal of Aging and Health, vol. 21, no. 7, pp. 967984, 2009.

[35] J. Kwak and J. R. Salmon, "Attitudes and preferences of Korean-American older adults and caregivers on end-of-life care," Journal of the American Geriatrics Society, vol. 55, no. 11, pp. 1867-1872, 2007.

[36] M. B. Happ, E. Capezuti, N. E. Strumpf et al., "Advance care planning and end-of-life care for hospitalized nursing home residents," Journal of the American Geriatrics Society, vol. 50, no. 5, pp. 829-835, 2002.

[37] B. Kahana, A. Dan, E. Kahana, and K. Kercher, "The personal and social context of planning for end-of-life care," Journal of the American Geriatrics Society, vol. 52, no. 7, pp. 1163-1167, 2004.

[38] J. Kwak and W. E. Haley, "Current research findings on endof-life decision making among racially or ethnically diverse groups," Gerontologist, vol. 45, no. 5, pp. 634-641, 2005.

[39] K. S. Johnson, M. Kuchibhatla, and J. A. Tulsky, "What explains racial differences in the use of advance directives and attitudes toward hospice care?" Journal of the American Geriatrics Society, vol. 56, no. 10, pp. 1953-1958, 2008.

[40] N. A. Hawkins, P. H. Ditto, J. H. Danks, and W. D. Smucker, "Micromanaging death: process preferences, values, and goals in end-of-life medical decision making," Gerontologist, vol. 45, no. 1, pp. 107-117, 2005. 


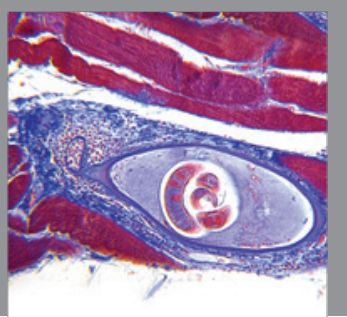

Gastroenterology

Research and Practice
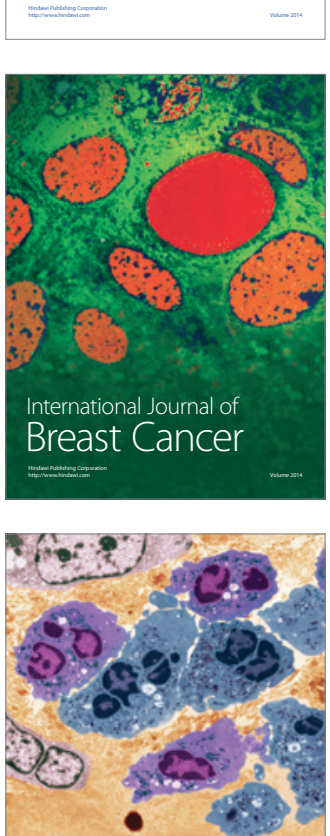

International Journal of Inflammation
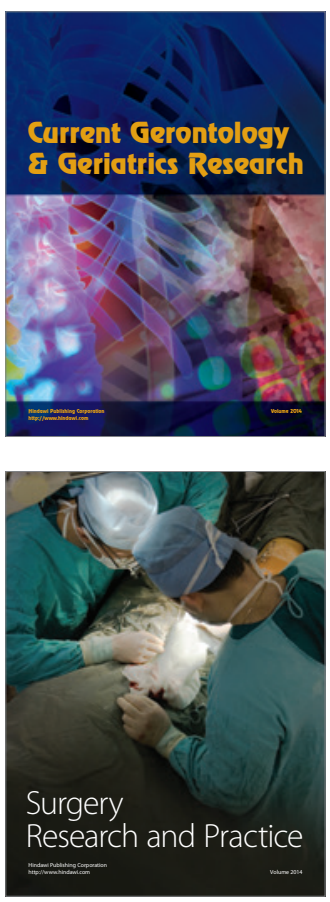
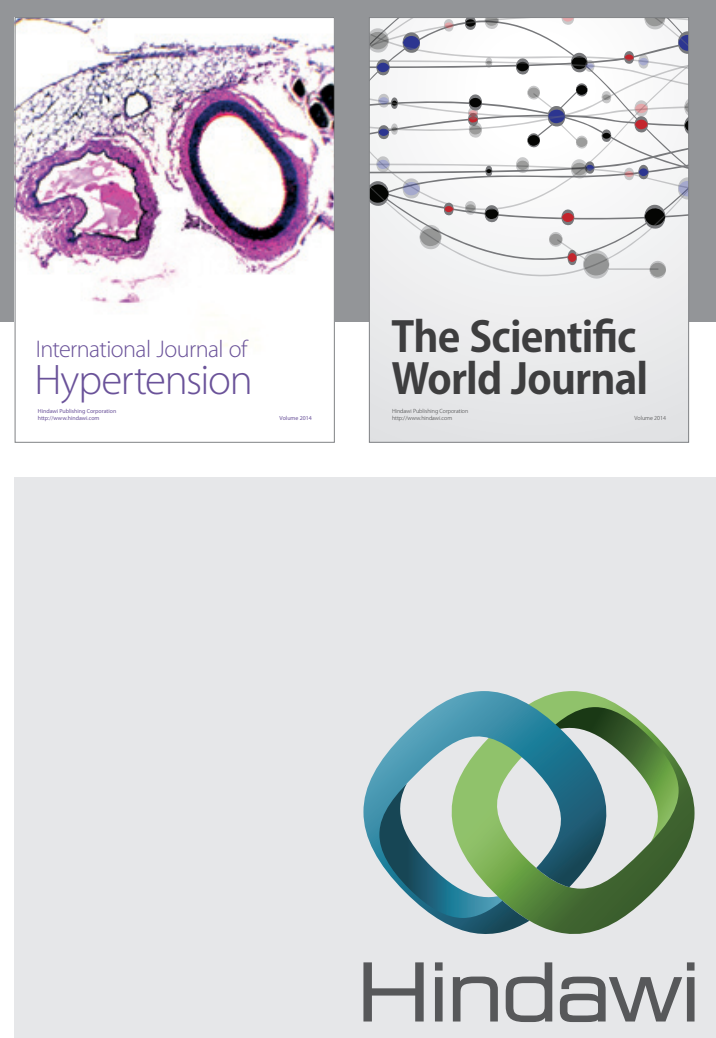

Submit your manuscripts at

http://www.hindawi.com
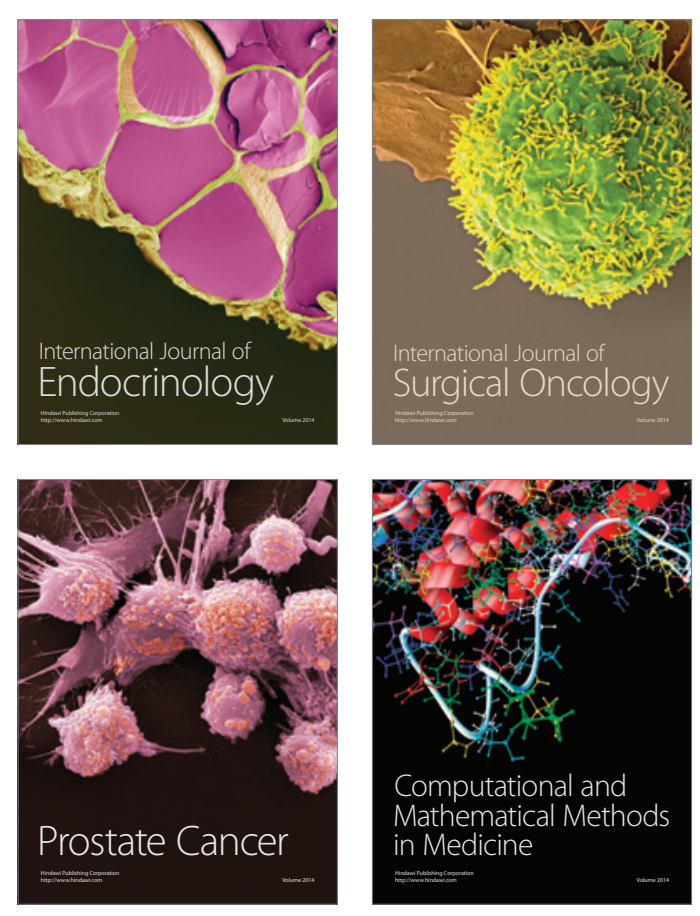
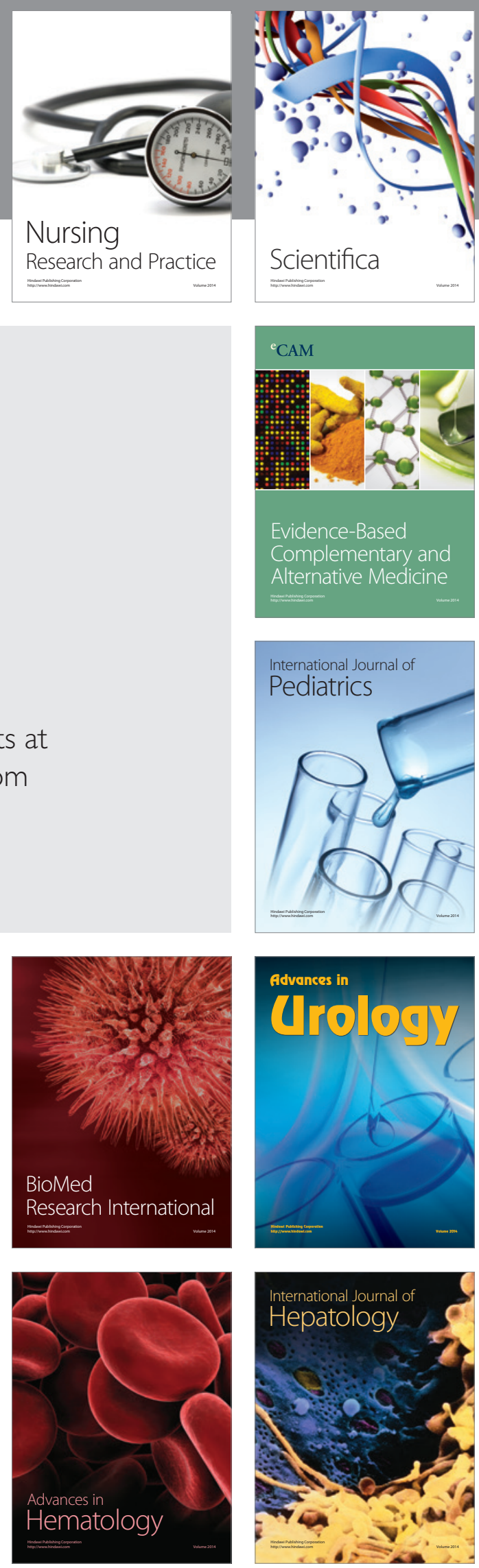